\title{
Relative improvements in flame resistance of coir fiberboards treated with fire-retardant solution
}

\author{
C. R. Rejeesh ${ }^{1}$ (D) K. K. Saju ${ }^{2}$
}

Received: 29 January 2018 / Accepted: 29 June 2018 / Published online: 23 July 2018

(c) The Japan Wood Research Society 2018

\begin{abstract}
In this study, medium-density coir fiberboard samples treated with fire-retardant (FR) solutions were found to be effective in resisting fires. This study sought the most favorable combination of FR boron solution for imparting flame resistance to coir fiberboards. The samples were chemically treated with FR solutions of various combinations of borax and boric acid. The treated samples showed substantial improvements in their resistance to flammability and flame penetration time, a reduced rate of burning, and a higher resistance to spread of flame. A regression analysis was performed to determine the relationship between the weight percentage of FR boron present in the solution and the flame resistance characteristics of treated coir fiberboards, in which the predictions were found to be accurate, within $\pm 3 \%$. The study concluded that any difference in the weight percentage of FR boron in the solution affected the flame resistance, and a solution that contained 35\% boron imparted maximum fire resistance to coir fiberboard samples.
\end{abstract}

Keywords Fire-retardant treatment $\cdot$ Flame resistance $\cdot$ Boron $\cdot$ Coir fiberboard $\cdot$ Regression analysis

\section{Introduction}

The ever-increasing demand for new biodegradable and sustainable raw materials has encouraged both manufacturers and engineers of the wood products industry to focus on renewable, alternative resources for an eco-friendly environment. Wood and its substitutes remain the major raw materials in the furniture and construction industries, while composite panel board manufacturing accounts for one of the fastest growing sectors of the wood and allied product industries. Among natural fibers, wood has been the most extensively used reinforcement in polymer matrices. However, due to expensive manufacturing processes and the desire for sustainability, a shift in interest has occurred towards other sustainable natural fibers that would, otherwise, be treated as agro-wastes [1-3]. Coir fiber is a biodegradable natural fiber extracted from the fibrous husks (mesocarp) of the seeds of coconut palms (Cocos nucifera L.). Coir fiber has

$\triangle$ C. R. Rejeesh

rejeeshcr@ fisat.ac.in

1 Mechanical Engineering Department, Federal Institute of Science and Technology, Kerala, India

2 School of Engineering, Cochin University of Science and Technology, Kerala, India traditionally been used for manufacturing ropes, carpets, or mattresses, but it is also useful for manufacturing composite panel boards. These fiberboards can substitute for wood and other engineered wood products in a range of applications from packaging to construction materials. Natural fibers like coir can substitute for synthetic fibers in a variety of applications. In addition to exhibiting good mechanical and acoustical properties, they are also biodegradable and buoyant [4]. Coconuts are grown in around 90 countries in the world, and the total annual production of coir fiber is 877,100 tons [4, 5]. The coir composite panel board is a structural composite material made from coir needled felt that is bonded together with phenol formaldehyde resin; it is a useful substitute for wood and other wood composites [4].

Coir fiber, being a lignocellulosic material, is flammable, and fires can propagate promptly. Coir fiber has evident environmental and sustainability benefits over its synthetic counterparts, and applying flame retardants could further help in meeting relevant fire standards $[6,7]$. Reducing the risk of fire also contributes to substantial improvements in quality of living. A fire accident and the successive combustion of wood, or any wood substitutes, in habitable structures like high-rise apartment buildings and other skyscrapers can be life-threatening. To reduce the risks of flammability and improve safety, composite panel boards can be treated with 
fire-retardant (FR) chemicals [8]. Fire resistance of composite panel boards is an important concern as the market for structural panel boards expands; these products are being used in wider and more demanding applications, including the construction sector and the furniture industry. It is widely accepted that the fire performance of wood-based composites can be considerably improved through various chemical treatments, making them suitable for a variety of applications. Fire-retardant-treated (FRT) panel board products are gaining acceptance where an improved level of fire safety is desired [9].

Borates are naturally found in the earth as compounds of boron. Two of these minerals, borax (BX) and boric acid (BA), are particularly well suited for use as flameretardant materials due to their complementary flameretardant characteristics. Their low toxicity to humans and the environment makes them qualified for use as flame retardants in residential settings [10]. BA, BX, and their combinations have been widely used in the fire protection industry due to their thermal resistance because they reduce surface flame propagation [6]; they have low melting points and form a glassy film layer on the surface when exposed to extreme heat [10]. The presence of BX tends to eliminate flame spread but promotes glowing, while BA enhances carbonization and suppresses glowing; consequently, they exhibit a synergic effect when used in combination [11]. The mixtures of BA and BX are complementary nature and adding more $\mathrm{BX}$ can compensate for the adverse effects of $\mathrm{BA}$ on board strength, as it buffers the acidic $\mathrm{pH}$ to neutral $\mathrm{pH}$ levels [12]. An estimated loading levels of at least 7.5\% boron are required for the material to be flame-retardant post-treatment [13].

Unlike various species of solid wood that are affected by microorganisms, coir composite boards show a higher resistance to biodeterioration. However, they are still susceptible to biological attack under favorable conditions. FR chemicals in treated panels are susceptible to leaching from moisture when exposed to weathering, and it decreases the effectiveness of the chemical against biodeterioration [10]. Boron-based compounds are particularly effective for cellulosic materials, and their neutral $\mathrm{pH}$, preservative effectiveness, and relatively low impact on mechanical properties make them a desirable choice as a fire retardant. They are also well known for their excellent protective characteristics against biodegrading microorganisms like termites [13].

In a scenario where the usefulness and viability of the mass-scale production of biocomposite materials are still debated, it is critical to ensure that the material is compatible with various treatments and is capable of self-extinguishing any fire, making it suitable for a variety of functions. Several attempts have been made to improve the fire resistance of natural fiber-based composite panel boards by treatment with different FR additives, and boron has been extensively reported for this purpose. Nevertheless, it is unlikely to conclude that all lignocellulosic materials behave in a generalized manner when treated with boron. This study primarily aims at determining an optimum concentration of boron-based FR solution for the chemical treatment of coir composite panel boards to have a positive effect on fire resistance. It also attempts to establish a relation between the boron present in an FR solution and the performance of composite board materials when exposed to fire.

\section{Experimental}

\section{Materials}

Coir fiber-based panel boards designated as medium-density coir boards, as per IS 15491:2004 [14], were prepared and chemically treated using an aqueous preservative solution containing combinations of laboratory grade $\mathrm{BA}\left(\mathrm{H}_{3} \mathrm{BO}_{3}\right.$; Merck Specialties Pvt. Ltd., Mumbai, India) and $\mathrm{BX}$ $\left(\mathrm{Na}_{2} \mathrm{~B}_{4} \mathrm{O}_{7} \cdot 10 \mathrm{H}_{2} \mathrm{O}\right.$; Nice Chemicals Pvt. Ltd., Kochi, India). The chemically treated samples were then subjected to various fire-resistance tests to assess the relative improvements in their flame resistance.

\section{Preparation of coir composite boards}

Medium-density coir composite boards were manufactured as per IS 15491: 2004 [14] via hot-pressing coir fiber mats impregnated with phenol formaldehyde resin. Coir fibers from coconut husk (Cocos nucifera L.) were extracted and prepared as per IS 9308: 1999 [15], and fed through a needle felt machine to make uniform non-woven fiber mats with appropriate density. Fine jute fibers were carded and spread to form a uniform layer. The fiber mats thus produced were impregnated with phenol formaldehyde resin and dried before processing. After drying, the impregnated fiber mats are stacked, one atop the other, for the required thickness and density in a hydraulic hot press (Srichakra Engineering Equipments, Bangalore, India), and are pressed at a temperature of $140{ }^{\circ} \mathrm{C}$ and a pressure of $1.17 \mathrm{MN} / \mathrm{m}^{2}$ for about $5 \mathrm{~min}$ to form coir composite boards with an average density of $650 \mathrm{~kg} / \mathrm{m}^{3}$.

\section{Chemical treatment}

Different levels of boron, from $10 \%$, were added to water to form solutions until maximum solubility was achieved. The maximum solubility of BA and BX in water without precipitation was observed with a combination of $15 \% \mathrm{BA}$, $20 \% \mathrm{BX}$, and $65 \%$ water, yielding approximately $35 \%$ boron in the FR solution (Table 1). Any addition of boron beyond this combination was found to be not fruitful as it seldom 
Table 1 Composition of FR solutions

\begin{tabular}{llll}
\hline Sample & Water $(\%)$ & BX $(\%)$ & BA (\%) \\
\hline FRCS 1 (40\% boron) & 60 & 23 & 17 \\
FRCS 2 (35\% boron) & 65 & 20 & 15 \\
FRCS 3 (30\% boron) & 70 & 18 & 12 \\
FRCS 4 (25\% boron) & 75 & 15 & 10 \\
FRCS 5 (20\% boron) & 80 & 12 & 8 \\
FRCS 6 (15\% boron) & 85 & 9 & 6 \\
FRCS 7 (10\% boron) & 90 & 6 & 4 \\
\hline
\end{tabular}

$F R C S$ fire-retardant chemical solution, $F R$ fire-retardant, $B X$ borax, $B A$ boric acid

dissolved completely into solution and the remaining existed as precipitate in the solution.

Coir board samples were cut into suitable dimensions required for various fire-resistance tests and were then FRtreated using an accelerated hot-and-cold bath method without affecting the laminate. The samples to be tested was immersed in FR solution at $100{ }^{\circ} \mathrm{C}$ for $30 \mathrm{~min}$ and then transferred to the cold bath where it was dipped in FR solution at $38{ }^{\circ} \mathrm{C}$ for $6 \mathrm{~h}$. Later, the samples were dried in sunlight to control the moisture content level within $5-7 \%$ of their weight [6]. During the initial phase of treatment, air present in the sample expands as a result of heating and is driven out, while the residual air in the sample contracts during the subsequent cooling stage, creating a partial vacuum that allows the preservative boron to penetrate the coir fiberboard. When treated with an FR solution having combination of BA and BX for maximum solubility, the average density of coir boards increased from 650 to $846 \mathrm{~kg} / \mathrm{m}^{3}$ and coir boards exhibited an average retention of $140 \mathrm{~kg} / \mathrm{m}^{3}$.

\section{Methods}

\section{Determination of fire resistance}

To investigate the degree of fire resistance imparted to the samples after FR treatment, a combination of fire-resistance tests which includes a flammability test, a flame penetration test, and a rate of burning test was conducted as per IS 1734: 1983 [16]. In addition, a resistance to spread of flame test was performed according to IS 15491: 2004 [14].

Flammability test A total of 48 specimens were subjected to the flammability test, with three trials performed for every set of samples. Two test specimens that measured $125 \mathrm{~mm} \times 125 \mathrm{~mm} \times 12 \mathrm{~mm}$ were prepared for each set of tests. The specimens were held vertically, $15 \mathrm{~mm}$ apart with one $40 \mathrm{~mm}$ higher than the other. Figure 1 shows the flammability test apparatus in operation, fixed with a Bunsen burner, so that the flame was directed against the inner face

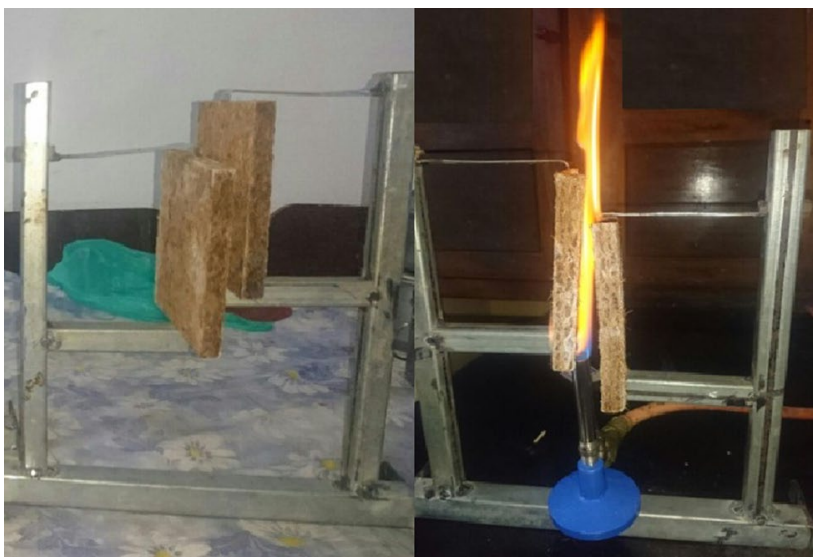

Fig. 1 Flammability test apparatus

of the specimens. Liquefied petroleum gas that was fed to the burner burned as a blue flame and ignited the face of the lower specimen, which in turn ignited the opposite face of the higher specimen. The response variable, flammability, was the time taken (min) for the higher specimen to be ignited after igniting the lower specimen. The specimen was deemed ignited if the burning was uninterrupted for at least $50 \mathrm{~s}$.

Flame penetration test Three trials were performed for each of the eight sets of samples, a total of 24 specimens, for the flame penetration tests. They were conducted on specimens that measured $125 \mathrm{~mm} \times 125 \mathrm{~mm} \times 12 \mathrm{~mm}$. The test specimens were held $50 \mathrm{~mm}$ above the nozzle of a Bunsen burner, as shown in Fig. 2, and the time taken for the flame to penetrate the thickness of each sample was recorded as the flame penetration time (min). The moment of penetration is identified as the exact time at which a visible flame is spotted on the opposite surface of the sample. The time taken for flame penetration shall not be less than 15 min for

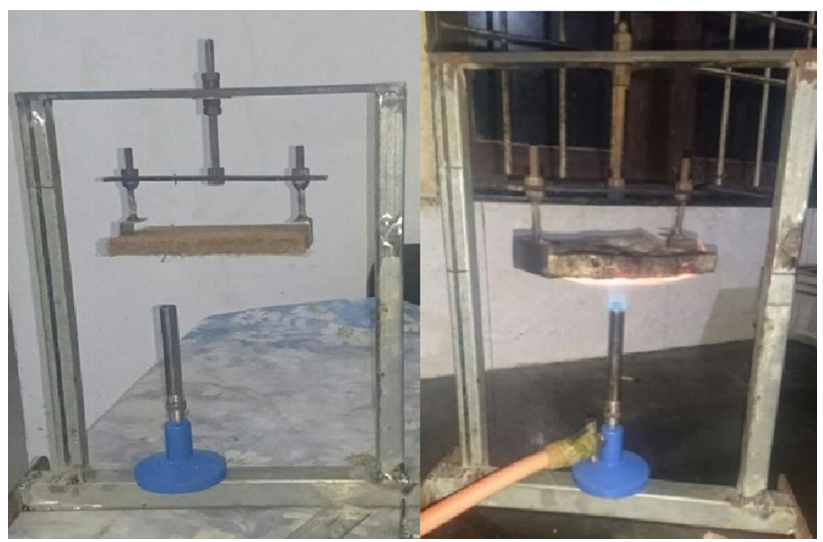

Fig. 2 Flame penetration test apparatus 
every $6 \mathrm{~mm}$ thickness, i.e., for a thickness ' $t$ ' $\mathrm{mm}$, the minimum time required for a sample to successfully pass flame penetration test would be $15 t / 6 \mathrm{~min}$.

Rate of burning test Three trials were performed for each of the eight sets of samples, a total of 24 specimens, for the rate of burning tests on specimens that measured $100 \mathrm{~mm} \times 12.5 \mathrm{~mm} \times 12 \mathrm{~mm}$. Figure 3 shows a test specimen ignited by a blue flame during the rate of burning test.

The test specimen was suspended vertically $30 \mathrm{~mm}$ from the nozzle of the burner. The weight of the sample was monitored throughout the test by keeping the whole arrangement in a sensitive-weighing scale, and the time taken for $10 \%$ loss in mass and all subsequent loss by $10 \%$ of the initial mass thereof was recorded. The time taken for the mass loss of sample from 30 to $70 \%$ was recorded for the purpose of comparison.

Resistance to spread of flame test The tests for determining resistance to spread of flame were performed according to IS 15491: 2004 [14]. The specimens tested measured $150 \mathrm{~mm} \times 25 \mathrm{~mm} \times 12 \mathrm{~mm}$. Three trials were performed for each of the eight sets of samples, for a total of 24 specimens. Figure 4 shows the setup for this test.

The samples held at an angle of $45^{\circ}$ to the horizontal and $50 \mathrm{~mm}$ away from the nozzle of the burner were exposed to a Bunsen burner flame intermittently for $30 \mathrm{~s}$, and the cycle was repeated until ignition. The ignited sample subsequently burning for more than $20 \mathrm{~s}$ suggests flame spread. The times for which the coir fiberboard samples were able to withstand ignition and flame spread were recorded to compare the resistance to flame spread.

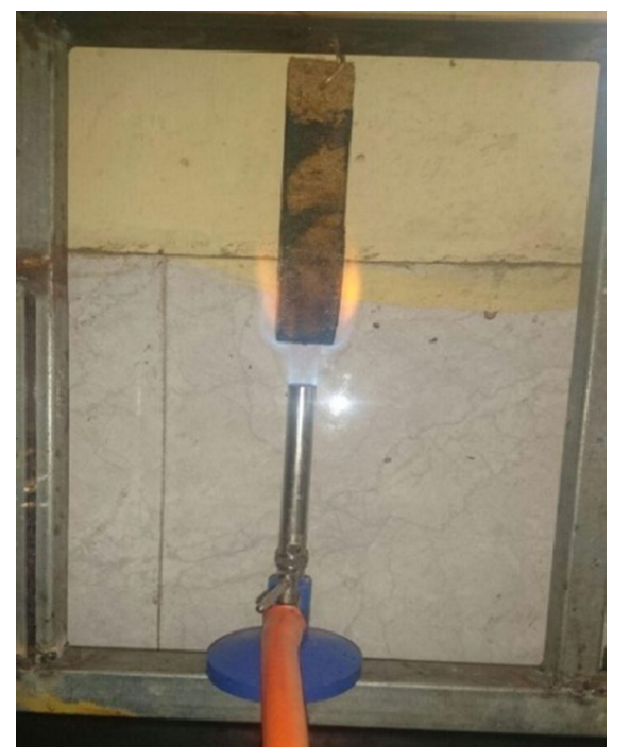

Fig. 3 Rate of burning test apparatus

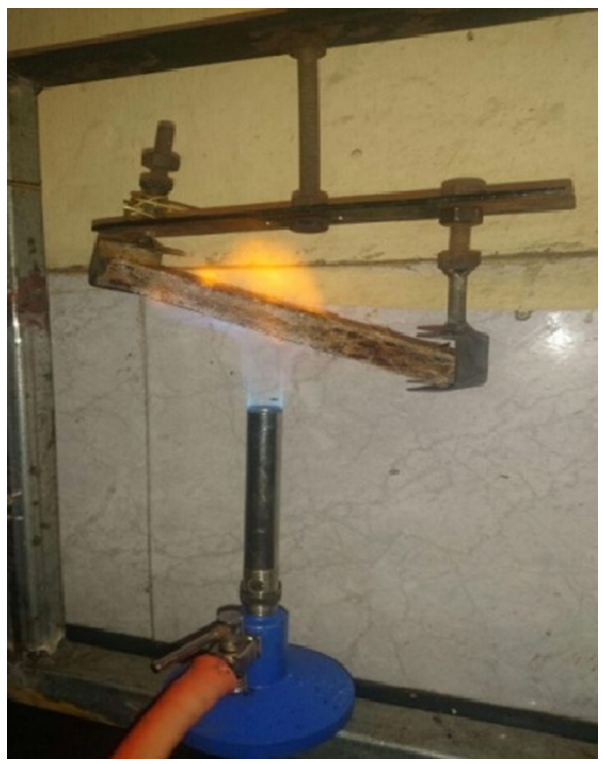

Fig. 4 Resistance to spread of flame test apparatus

\section{Regression analysis}

A regression analysis was performed to investigate the extent to which the weight percentage of boron present in the FR solution predicted the fire resistance of the mediumdensity coir fiberboards. The program used was Minitab 17 (Minitab, Inc., State College, PA, USA). Linear, quadratic, and cubic regression models were all considered for analysis. Of those, it was found that the cubic model gave the best fit and most accurate predictions. Therefore, a thirddegree polynomial (cubic) regression model was used with the weight percentage of boron compounds present in FR solution as predictor $(X)$ and the results of the various fireresistance tests (in $\mathrm{min}$ ) as the responses $(Y)$. The relationships between the predictor $(X)$, i.e., weight percentage of boron present in the solution and the different responses $(Y)$, i.e., the values for flammability, flame penetration, rate of burning, and resistance to flame spread, were investigated. The significance threshold was set at $p<0.05$ for all four of the fire performance tests. Because fire resistance is a collective measure of different fire-resistance tests, each test was analyzed separately in the regression analysis.

Confirmation of regression analysis The obtained results indicated that the fire performance is a maximum when there is $30-35 \%$ boron compounds present in the FR solution. Therefore, three set of coir fiberboard samples were chemically treated with a solution that contained 33\% boron compounds (19\% BX and 14\% BA) and 67\% water and confirmation experiments were performed with all four of the fire performance tests to assess the validity of the regression analysis. 


\section{Results and discussion}

The various physical Boron-treated samples can offer greater resistance to fire and flame propagation than untreated samples of wood and other engineered wood products, such as plywood, which contain combustible organic carbon and hydrogen compounds. The general procedures practiced for the preservation and treatment of wood for extended life and fire resistance were expected to hold well for medium-density coir fibreboard samples as well, due to the presence of common constituents such as lignin, cellulose, or hemicelluloses in the structure. The effects of treatment of coir composite boards with an FR solution containing boron compounds were encouraging, with a better fire resistance than untreated samples.

\section{Flammability time}

A regression analysis was performed to predict the flammability of coir fiberboards after treatment with a solution of varying concentrations of FR boron compounds.

A regression equation was generated with $F(3,20)=187.16$, $p<0.001$, and $R^{2}=96.6 \%$. Figure 5 shows a fitted curve plot with flammability $(\mathrm{min})\left(Y_{1}\right)$ as the ordinate and $\mathrm{wt} \% \mathrm{FR}$ boron $(X)$ as the abscissa.

The regression equation used to predict flammability was:

$Y_{1}=34.19-2.543 X+0.1928 X^{2}-0.002989 X^{3}$.

\section{Flame penetration time}

A regression equation was generated with $F(3,20)=34.31$, $p<0.001$, and $R^{2}=83.7 \%$. Figure 6 shows a fitted curve plot with flame penetration time $(\mathrm{min})\left(Y_{2}\right)$ as the ordinate and $\mathrm{wt} \%$ FR boron $(X)$ as the abscissa.

The regression equation used to predict flame penetration time of the coir fiberboard samples was:

$Y_{2}=27.05-0.4014 X+0.05477 X^{2}-0.000929 X^{3}$.

\section{Rate of burning}

A regression equation was generated with $F(3,20)=63.33$, $p<0.001$, and $R^{2}=90.5 \%$. Figure 7 shows a fitted curve plot with rate of burning ( $\min )\left(Y_{3}\right)$ as the ordinate and $\mathrm{wt} \% \mathrm{FR}$ boron $(X)$ as the abscissa.

The regression equation that predicted the rate of burning of the samples was:

$Y_{3}=12.49-0.6698 X+0.1472 X^{2}-0.002829 X^{3}$.

\section{Resistance to flame spread}

A regression equation was generated with $F(3,20)=179.62$, $p<0.001$, and $R^{2}=96.4 \%$. Figure 8 shows a fitted curve plot with the resistance to flame spread $(\mathrm{min})\left(Y_{4}\right)$ as the ordinate and wt\% FR boron $(X)$ as the abscissa.

The regression equation used to predict the resistance to flame spread was:

$Y_{4}=7.071+5.936 X-0.2007 X^{2}+0.002125 X^{3}$.

\section{Optimum composition of boron compounds in FR solution}

Table 2 consolidates the results of the fire-resistance tests. These data were investigated using a regression analysis to determine relationships between the weight percentage of boron compounds and the results of the different
Fig. 5 Fitted curve of flammability vs. weight percentage of boron compounds present in fire-retardant (FR) solution

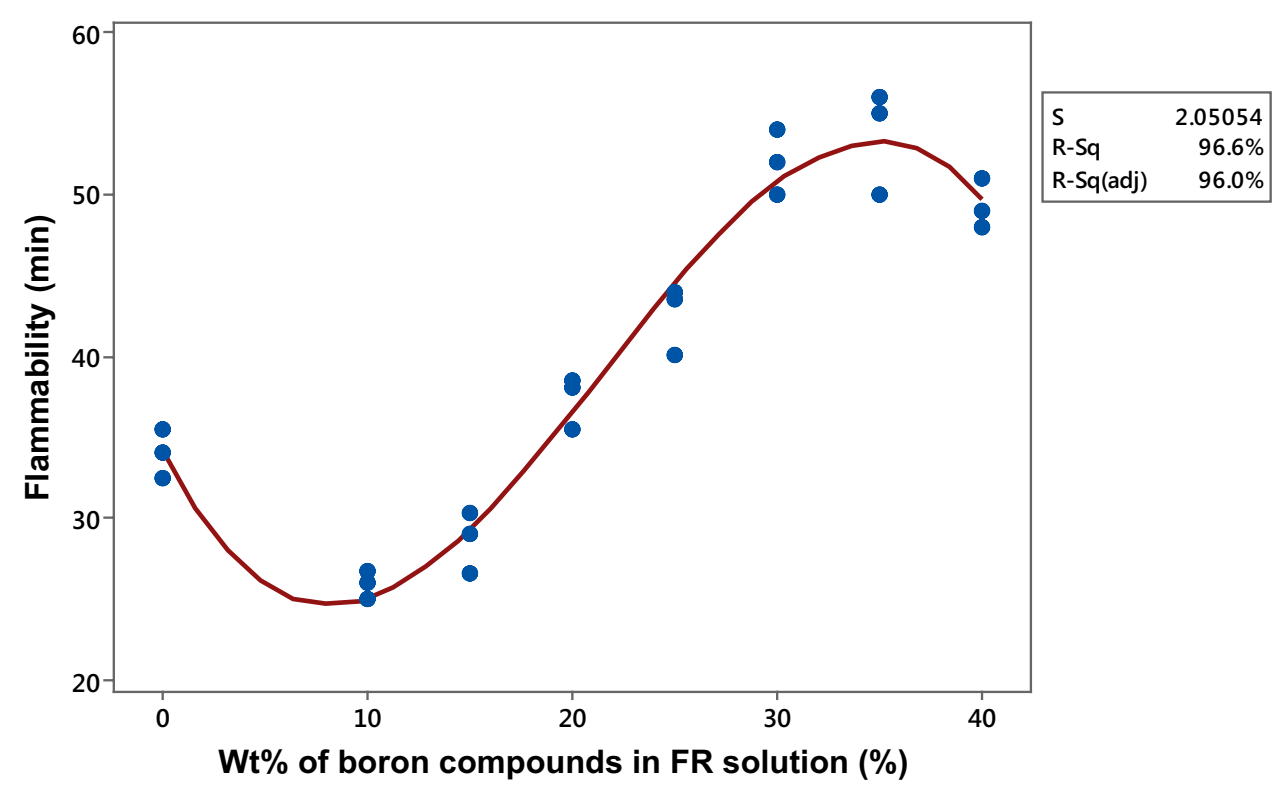


Fig. 6 Fitted curve of flame penetration time vs. weight percentage of boron compounds present in fire-retardant (FR) solution

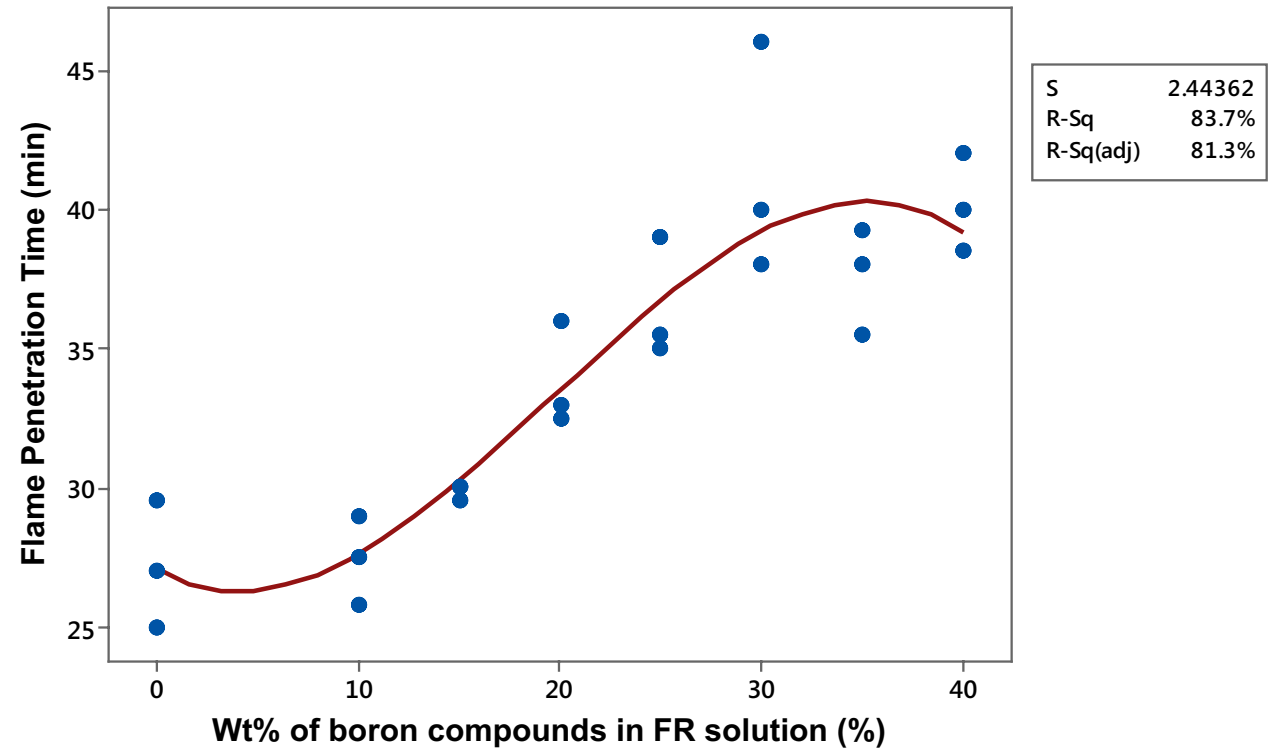

Fig. 7 Fitted curve of rate of burning vs. weight percentage of boron compounds present in fire-retardant (FR) solution

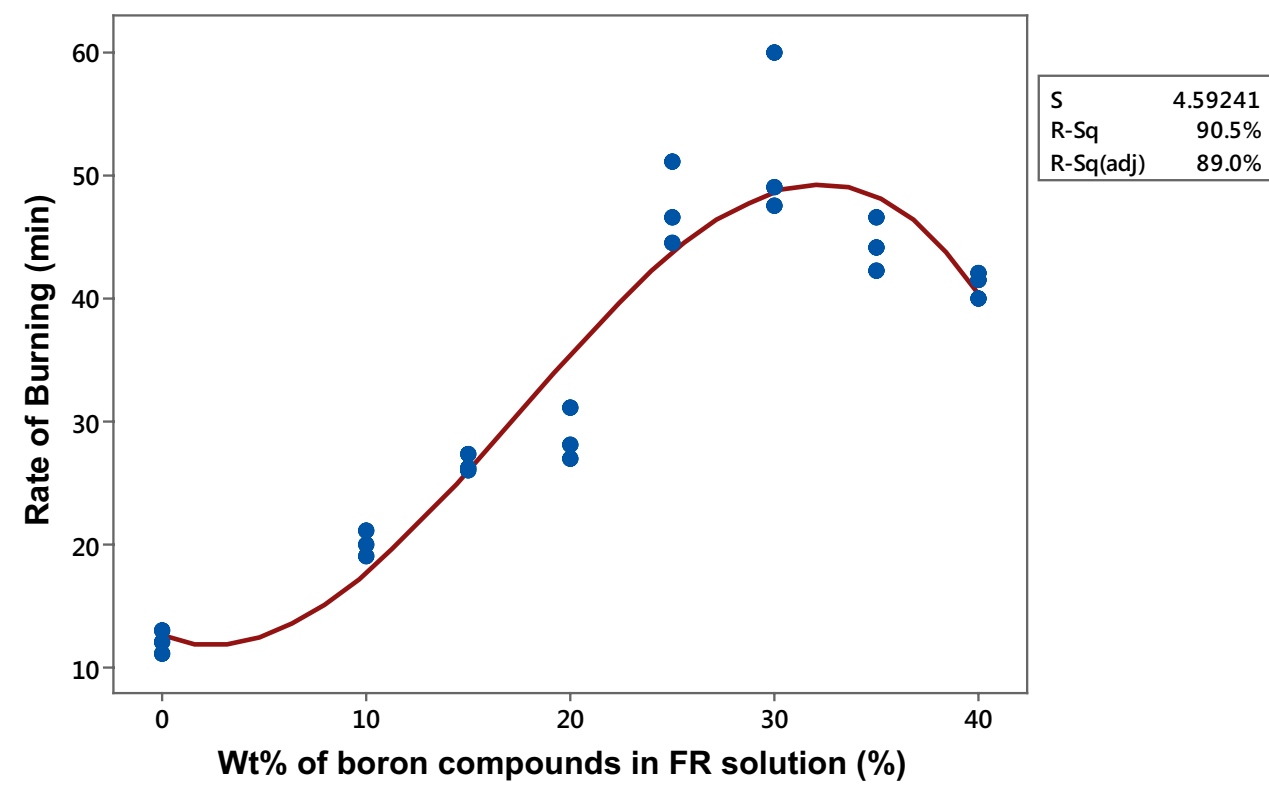

fire-resistance tests. It was seen from the data that the chemically treated medium-density coir fibreboard samples gained notable resistance to ignition and flame spread when compared to the untreated samples. It suggests that a fire-retardant chemical solution (FRCS) having boron compounds between 25 and $35 \%$ of the total weight of the solution imparted the highest flame resistance to coir fiberboards. The peak values for the flame penetration, rate of burning, and flame spread tests were exhibited by coir fiberboard samples treated with a $30 \%$ boron solution, designated as FRCS 3, while the samples treated with a $35 \%$ boron solution, designated as FRCS 2, exhibited the maximum value for the flammability test.
Table 3 shows the prescribed minimum time to pass each test and gives a fair reference for judging the values exhibited in Table 2 for each test. It also helps in determining if the presence or differences in the weight percentage of boron can contribute to flame resistance of the material.

The regression-derived equations (1)-(4) were used to predict the values of flammability, flame penetration, rate of burning, and flame spread for coir fiberboards treated by solutions with FR boron compounds between 25 and $35 \mathrm{wt} \%$. The regression analysis predicted the maximum values for the flammability and flame penetration tests for samples treated with $35 \mathrm{wt} \%$ boron solution. The predicted values of rate of burning were found to be a maximum for the samples treated with $33 \%$ boron solution. However, 
Fig. 8 Fitted curve of resistance to flame spread vs. weight percentage of boron compounds present in fire-retardant (FR) solution

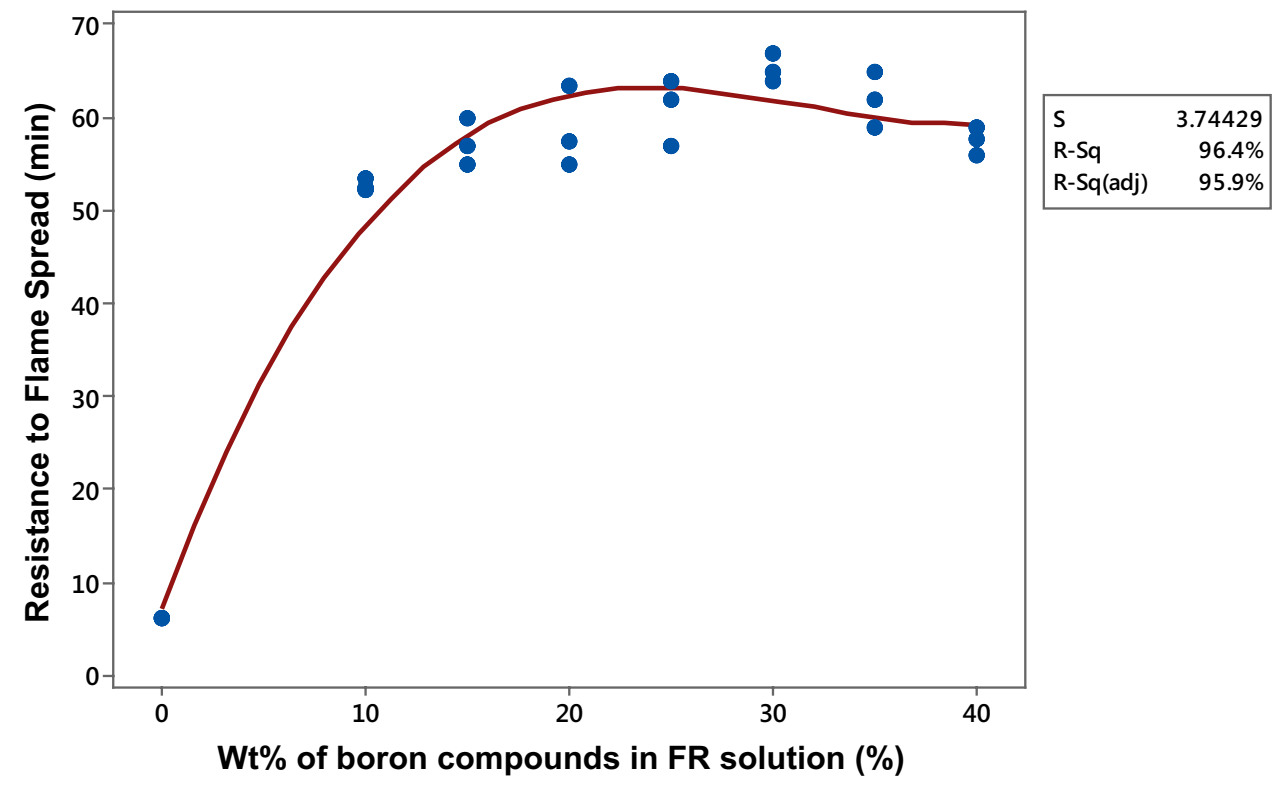

Table 2 Fire-resistance test results

\begin{tabular}{|c|c|c|c|c|c|}
\hline Sample & FR boron $(w t \%)$ & \multicolumn{2}{|c|}{ As per IS 1734: Part 3 (1983) [16] } & Rate of burning (min) & $\begin{array}{l}\text { Resistance to flame spread (min) } \\
\text { As per IS 15491: } 2004 \text { [14] }\end{array}$ \\
\hline \multirow[t]{3}{*}{ FRCS 1} & \multirow[t]{3}{*}{40} & 49.00 & 38.50 & 41.50 & 56.00 \\
\hline & & 51.00 & 42.00 & 40.00 & 57.75 \\
\hline & & 48.00 & 40.00 & 42.00 & 59.00 \\
\hline \multirow[t]{3}{*}{ FRCS 2} & \multirow[t]{3}{*}{35} & 55.00 & 38.00 & 42.25 & 65.00 \\
\hline & & 56.00 & 35.50 & 44.00 & 62.00 \\
\hline & & 50.00 & 39.25 & 46.50 & 59.00 \\
\hline \multirow[t]{3}{*}{ FRCS 3} & \multirow[t]{3}{*}{30} & 52.00 & 40.00 & 47.50 & 65.00 \\
\hline & & 54.00 & 38.00 & 49.00 & 67.00 \\
\hline & & 50.00 & 46.00 & 60.00 & 64.00 \\
\hline \multirow[t]{3}{*}{ FRCS 4} & \multirow[t]{3}{*}{25} & 44.00 & 35.00 & 44.50 & 62.00 \\
\hline & & 43.50 & 35.50 & 51.00 & 64.00 \\
\hline & & 40.00 & 39.00 & 46.50 & 57.00 \\
\hline \multirow[t]{3}{*}{ FRCS 5} & \multirow[t]{3}{*}{20} & 38.00 & 33.00 & 28.00 & 57.50 \\
\hline & & 38.50 & 32.50 & 31.00 & 63.50 \\
\hline & & 35.50 & 36.00 & 27.00 & 55.00 \\
\hline \multirow[t]{3}{*}{ FRCS 6} & \multirow[t]{3}{*}{15} & 30.25 & 30.00 & 26.00 & 57.00 \\
\hline & & 26.50 & 30.00 & 26.15 & 55.00 \\
\hline & & 29.00 & 29.50 & 27.25 & 60.00 \\
\hline \multirow[t]{3}{*}{ FRCS 7} & \multirow[t]{3}{*}{10} & 26.75 & 27.50 & 21.00 & 52.25 \\
\hline & & 25.00 & 29.00 & 19.00 & 52.50 \\
\hline & & 26.00 & 25.75 & 20.00 & 53.50 \\
\hline \multirow[t]{3}{*}{ Untreated } & \multirow[t]{3}{*}{0} & 34.00 & 25.00 & 12.00 & 6.00 \\
\hline & & 32.50 & 27.00 & 13.00 & 6.00 \\
\hline & & 35.50 & 29.50 & 11.00 & 6.00 \\
\hline
\end{tabular}

FRCS fire-retardant chemical solution, $F R$ fire-retardant 
Table 3 Prescribed minimum time to pass the tests

Test as per IS 1734: Part 3 (1983) [16]

Prescribed minimum time as per IS 5509 (2000) [17]

Flammability

Not less than $30 \mathrm{~min}$

Time taken for second specimen to ignite after the first, lower specimen ignites

Flame penetration

Time taken for flame penetration from bottom to top surface

Rate of burning

Time taken for weight to decrease from 70 to $30 \%$

Test as per IS 15,491 (2004) [14]

Resistance to spread of flame

Time taken for the specimen to be ignited and of sustained burning

Not less than $15 t / 6=30 \mathrm{~min}$ where thickness of sample, $(t)=12 \mathrm{~mm}$

Not less than $20 \mathrm{~min}$

Prescribed minimum time as per IS 15491 (2004) [14]

No minimum time prescribed for ignition, but no burning after ignition shall continue for more than $20 \mathrm{~s}$

Table 4 Results of confirmation test with 33\% boron FR solution

\begin{tabular}{lllll}
\hline & $\begin{array}{l}\text { Flam- } \\
\text { mability } \\
(\mathrm{min})\end{array}$ & $\begin{array}{l}\text { Flame pen- } \\
\text { etration time } \\
(\mathrm{min})\end{array}$ & $\begin{array}{l}\text { Rate of } \\
\text { burning } \\
(\mathrm{min})\end{array}$ & $\begin{array}{l}\text { Resistance to } \\
\text { flame spread } \\
(\mathrm{min})\end{array}$ \\
\hline $\begin{array}{c}\text { Measured } \\
\text { values }\end{array}$ & 52.0 & 40.0 & 49.0 & 62.0 \\
$\begin{array}{c}\text { Predicted } \\
\text { values }\end{array}$ & 53.2 & 40.0 & 47.8 & 60.6 \\
\hline
\end{tabular}

flame spread was largely unaltered by the variations in boron for the FR treatment and only slight variations were present among their values which conform to the treatment with $30 \%$ boron solution.

Table 4 shows both the measured values and regressionpredicted values for all fire-resistance characteristics of coir fiberboard samples treated with a solution containing 33\% boron compounds (19\% BX and 14\% BA) and 67\% water. The predictions were accurate, within $\pm 3 \%$. The results suggested the use of a combination of BA and BX in a 1:1.5 ratio for maximum solubility in water $[6,7]$. The solution containing 35\% boron compounds (15\% BA and 20\% BX) and $65 \%$ water imparted maximum fire resistance to coir fiberboard samples.

\section{Conclusion}

This study evaluated the flame resistance of chemically treated coir composite panel boards with different weight percentages of borates in the solutions and identified an optimal solution composition. Regression analysis successfully predicted the values of flammability, flame penetration, rate of burning, and resistance to flame spread tests with respect to the weight percentage of FR boron present in the solution for chemical treatment, and the equations which fit were found to be statistically significant. An aqueous solution containing $35 \%$ boron compounds (15\% BA and 20\% BX) imparted substantial fire resistance to FRT coir fiberboards.

\section{References}

1. Mohanty AK, Misra M, Drzal LT (2002) Sustainable bio-composites from renewable resources: opportunities and challenges in the green materials world. J Polym Environ 10(1-2):19-26

2. Asokan P, Saxena M, Asolekar SR (2007) Solid wastes generation in India and their recycling potential in building materials. Build Environ 42(6):2311-2320

3. Madurwar MV, Ralegaonkar RV, Mandavgane SA (2013) Application of agro-waste for sustainable construction materials: a review. Constr Build Mater 38:872-878

4. Rejeesh CR, Saju KK (2017) Methods and materials for reducing flammability behaviour of coir fibre based composite boards: a review. Mater Today-Proc 4(9):9399-9407

5. Food and Agriculture Organization (FAO) (2017) Jute, kenaf, sisal, abaca, coir and allied fibres: statistical bulletin 2016. Food and Agriculture Organization of the United Nations, Rome

6. Rejeesh CR, Saju KK (2017) Effect of chemical treatment on fireretardant properties of medium density coir fiber boards. Wood Fiber Sci 49(3):332-337

7. Rejeesh CR, Saju KK (2018) Effect of fire retardant treatment on mechanical properties of medium density coir composite boards. Wood Fiber Sci 50(1):113-118

8. Baysal E, Altinok M, Colak M, Ozaki SK, Toker H (2007) Fire resistance of Douglas fir (Pseudotsugamenzieesi) treated with borates and natural extractives. Bioresour Technol 98(5):1101-1105

9. Candan Z, Ayrilmis N, Dundar T (2012) Fire performance of LVL panels treated with fire retardant chemicals. Wood Res 57(4):651-658

10. Nagieb ZA, Nassar MA, El-Meligy MG (2011) Effect of addition of boric acid and borax on fire-retardant and mechanical properties of urea formaldehyde saw dust composites. Int J Carbohydr Chem 2011:1-6. https://doi.org/10.1155/2011/146763

11. Özdemir F, Tutus A (2013) Effects of fire retardants on the combustion behavior of high-density fiberboard. BioResources 8(2):1665-1674

12. Yalinkiliç MK, Imamura Y, Takahashi M, Demirci Z (1998) Effect of boron addition to adhesive and/or surface coating on fire-retardant properties of particleboard. Wood Fiber Sci 30(4):348-359 
13. LeVan SL, Tran HC (1990) The role of boron in flame-retardant treatments. In: Hamel M (ed) 1st international conference on wood protection with diffusible preservatives: proceedings, proceedings 47355, November 28-30, 1990. Nashville, TN, USA. 1990, pp 39-41

14. IS 15491 (2004) Medium density coir boards for general purposes - specification. Bureau of Indian Standards, New Delhi
15. IS 9308 (1999) Specification for mechanically extracted coir fibers. Bureau of Indian Standards, New Delhi

16. IS 1734 (1983) Methods of test for plywood, part 3: determination of fire resistance. Bureau of Indian Standards, New Delhi

17. IS 5509 (2000) Fire retardant plywood—specification. Bureau of Indian Standards, New Delhi 